\title{
HEART TROUBLE AND RACIAL GROUP IDENTITY: EXPLORING ETHNIC HETEROGENEITY AMONG BLACK AMERICANS
}

\author{
By \\ Helena Eyram Dagadu \\ Thesis \\ Submitted to the Faculty of the \\ Graduate School of Vanderbilt University \\ in partial fulfillment of the requirements \\ for the degree of
}

MASTER OF ARTS

in

Sociology

December, 2012

Nashville, Tennessee

Approved:

Professor C. André Christie-Mizell

Professor R. Jay Turner 


\section{ACKNOWLEDGEMENTS}

This work would not have been possible without the financial support of grant No. 68146 from the Robert Wood Johnson Foundation Center for Health Policy at Meharry Medical College. The content is solely the responsibility of the author and does not necessarily represent the official views of the Robert Wood Johnson Foundation. I

would like to especially thank my advisor and mentor, Prof. C. André Christie-Mizell, for his support and guidance throughout this process. I am also indebted to Prof. R. Jay Turner for inspiring this work and serving on my committee.

Finally, I am so grateful to Benjamin, who, through his unwavering faith and encouragement, has sustained me through this process. 


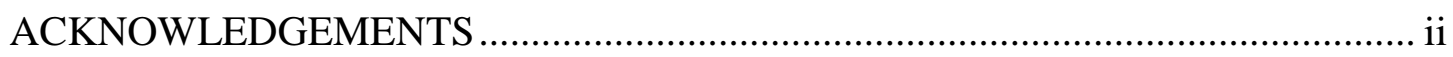

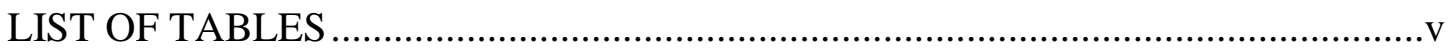

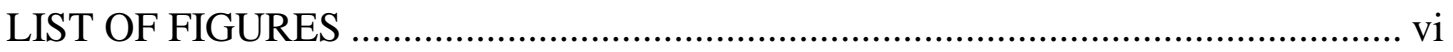

\section{Chapter I}

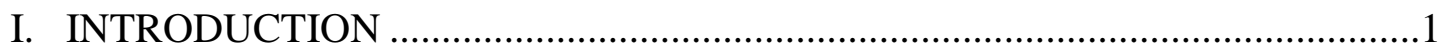

\section{Chapter II}

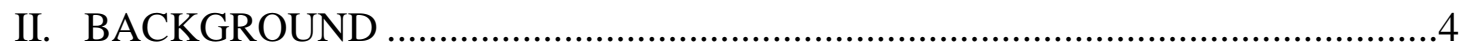

Theoretical framework .................................................................................

Heart trouble, racial group identity, and ethnic heterogeneity............................6

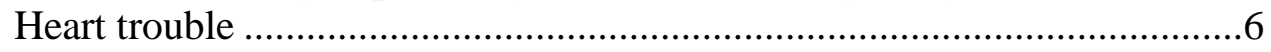

Racial group Identity .........................................................................

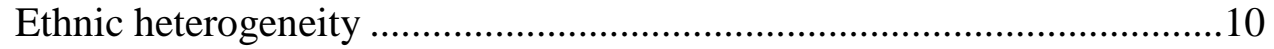

\section{Chapter III}

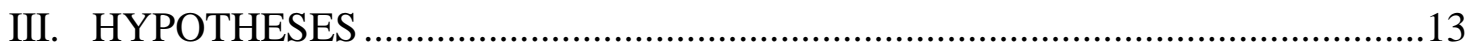

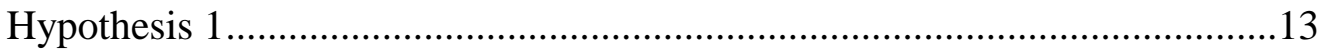

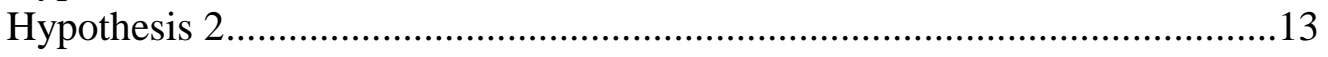

\section{Chapter IV}

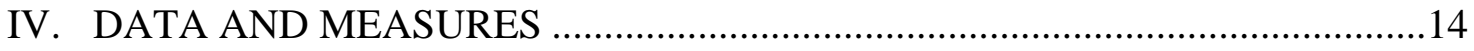

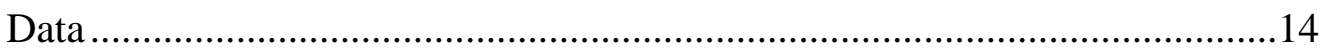

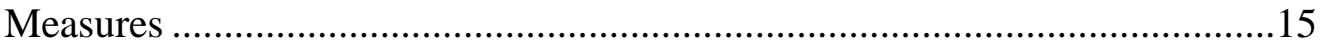

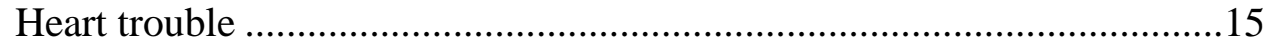

Racial group identity and ethnic heterogeneity ………….........................15

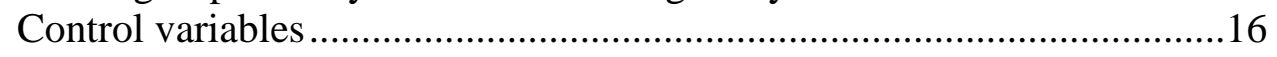

\section{Chapter V}




\section{Chapter VI}

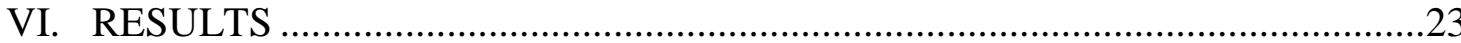

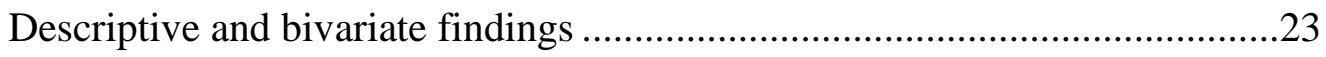

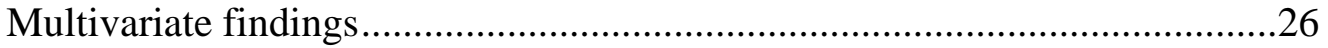

\section{Chapter VII}

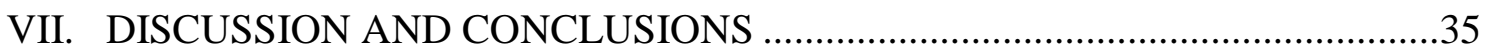

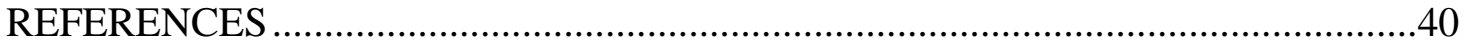




\section{LIST OF TABLES}

Table

Page

1. Weighted Means and Proportions of a National Survey of American

Life Sample of African Americans and Caribbean Blacks $(\mathrm{N}=2,137)$

2. Logistic Regression of Heart Trouble on Selected Variables, National Survey of American Life $(\mathrm{N}=2,137)$...

3. Logistic Regression of Heart Trouble on Selected Variables, National

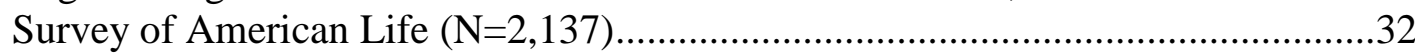




\section{LIST OF FIGURES}

Figure

Page

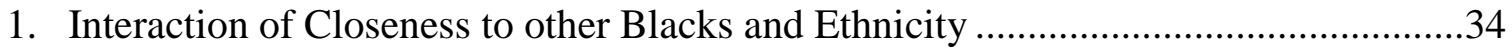




\section{CHAPTER I}

\section{INTRODUCTION}

What is the relationship between racial group identity and heart disease among Black Americans? Does this relationship vary by ethnicity? For over 90 years, heart disease has been the leading cause of death for both men and women in the United States, resulting in over 600,000 deaths per year (Centers for Disease Control; CDC 2012). Although heart disease encompasses a myriad of problems, the central issue is atherosclerosis, a condition characterized by a buildup of plaque in the walls of the arteries (American Heart Association 2012). Too often, the consequence of this buildup is a heart attack or stroke. Every year, approximately 785,000 Americans have their first heart attack, while another 470,000 with a history of one or more heart attacks have another attack (CDC 2012). In 2010, heart disease alone cost the U.S. nearly 109 billion dollars, including the cost of health care services, medications, and lost productivity (CDC 2012). Although its pathogenesis begins years earlier, health care providers typically first detect heart disease among individuals in middle to late adulthood (Mezuk 2010).

Compounding the problem of heart disease in the United States are racial differences. Racial health disparities in the U.S. have a long and protracted history and reveal differences in health outcomes between groups that reflect social inequalities (Frieden 2011; Read and Emerson 2005). Although the last 40 years has seen many improvements in the overall health of the general U.S. population, Black Americans 
remain disproportionately affected by poor health outcomes compared to their White counterparts (Chae et al. 2010; Read and Emerson 2005). Among all racial and ethnic groups in the U.S., Blacks have the highest morbidity and mortality for almost all diseases. These conditions include higher disability rates and shorter life expectancies (Feagin and McKinney 2003; Read and Emerson 2005). Moreover, disparities in heart disease are arguably one of the most recognized racial health disparities in the United States. Black Americans between the ages of 45 and 65 are two and a half times more likely to die from heart disease than White Americans in the same age range (Keenan and Shaw 2011). Although much research has attempted to account for these Black-White disparities, numerous questions about the origins, causes, and consequences remain.

Research seeking to address racial health disparities suggests that racial group identity is positively associated with better health outcomes. Specifically, research has found that positive Black racial group identity can minimize the risk of heart disease among Black Americans (Branscombe et al. 1999; Christie Mizell et al. 2010; Clark et al. 1999; LaVeist et al.2001; Shelton and Sellers 2000). In this paper, I focus on the U.S. Black population to explore whether racial group identity affects history of heart trouble. Additionally, I examine whether ethnicity among Black Americans shapes how racial group identity impacts history of heart trouble. My goal in this paper is to investigate whether racial identity impacts heart trouble differently for African Americans compared to Caribbean Blacks.

This study contributes to the literature on racial group identity and physical health in three important ways. First, although much work exists on Black-White health disparities, less is known about intragroup variation or ethnic heterogeneity among Black 
Americans. In much of the literature, the U.S. Black population is often portrayed as a monolith, sharing similar social characteristics and circumstances (Ida and ChristieMizell 2012; Williams et al. 2007a; Williams and Jackson 2000). For example, Southern African Americans, Jamaican Americans, and Ghanaian Americans are collectively labeled and categorized as "Black" in many research studies (Williams and Jackson 2000). Although there are important commonalities among groups in the U.S. that identify as Black, there are significant differences including ethnicity. Second, several studies indicate that racial group identity is an important factor in the well-being of minorities in the U.S. (Christie-Mizell et al. 2010; Ida and Christie-Mizell 2012). This study helps further clarify how race-related facets of the self can potentially be protective or serve as a psychosocial resource against heart disease. Finally, among various theoretical frameworks used to explain physical health outcomes, the stress process model has been underutilized. Therefore, I utilize the stress process to examine a physical health outcome, history of heart trouble. The model (Pearlin et al. 1981; Turner 2010) provides a useful framework to examine variation in heart disease between African Americans and Caribbean Blacks. For this study, individuals who identify as Black, but report no Caribbean ancestry are called African Americans. Caribbean Blacks are individuals that identify as Black and also report Caribbean ancestry. 


\section{CHAPTER II}

\section{BACKGROUND}

\section{Theoretical Framework}

This research is guided by the stress process model, first articulated by Pearlin et al. (1981) and elaborated by Turner (2010). Although used most often to examine mental health outcomes, the stress process model is broad enough in scope to identify and specify the interrelationships among stressors, psychosocial resources, and physical health outcomes such as heart disease (Jenkins 1979; Nerem et al. 1980; Rozanksi et al. 1999; Turner 2010; Vitaliano et al. 2002). Indeed, there is compelling evidence that psychosocial stressors influence mental and physical health through the same physiologic pathways (Geronimus et al. 2004; Griffith et al. 2011; Massey 2004; McEwen 1998; Pickering 1999; Seeman et al. 2001; Williams et al. 2003). According to Turner and Lloyd (1999), a central guiding assumption of the stress process model is that inequalities in health arise from patterned differences in social experiences. To the extent that important differences in personal histories and in current social conditions tend to be defined by social statuses such as ethnicity, race, gender, age, and socioeconomic status, it follows that relationships among these statuses and heart disease arise from status variations in stress exposure (Turner and Avison 2003). In other words, stress is neither randomly distributed in the U.S. population generally nor within the U.S. Black population specifically (Williams et al. 1997). Indeed, prior studies have found that Caribbean Blacks have health profiles that vary considerably from African Americans, 
whose experiences of stress as well as resources may be qualitatively different (Seaton et al. 2008; Williams et al., 2007a; Williams et al., 2007b; Williams and Jackson 2000).

In its basic form, the stress process model can be reduced to stressors, mediators and moderators, and outcomes. Stressors impact outcomes by taxing an individual's coping ability. Also, relevant for this study's examination of heart disease, stressors can cause cellular aging and exacerbate heart conditions (Epel et al. 2006; Williams and Mohammed 2009). Stressors also cause general wear and tear on the body, causing deregulation of multiple biological systems that can lead to premature illness and mortality (Seeman et al. 2004; Williams and Mohammed 2009). This study includes stressors that the literature indicates are associated with heart disease, racial group identity, and ethnicity, including day-to-day discrimination, major life discrimination, obesity, and smoking (CDC 2012; Williams et al. 1997).

Mediators and moderators are psychosocial resources (e.g., racial group identity, self-esteem, social support) that help reduce the deleterious effects of stressors. Moderators, which may decrease the damaging effects of stressors, are associated with the social positions people inhabit that determine their access to psychosocial resources. Finally, outcomes within the stress process model are the observed effects of stressors after accounting for the moderators (Pearlin et al. 1981; Ida and Christie-Mizell 2012). The outcome for this study is history of heart trouble. In this study, I develop a model that includes all components of the stress process model; however, the singular focus of this study is examining whether racial group identity is a psychosocial resource that decreases the probability of heart disease for Black Americans. Moreover, I seek to 
understand whether the potential protective effects of racial group identity vary by ethnicity for African Americans compared to Caribbean Blacks.

\section{Heart Trouble, Racial Group Identity, and Ethnic Heterogeneity}

Heart Trouble. Heart disease is persistently the leading cause of death for American men and women, with a greater proportion of men dying form heart disease than women (Keenan and Shaw 2011). Also known as cardiovascular disease, heart disease includes various problems, many of which stem from a buildup of plaque in the walls of arteries. This buildup or atherosclerosis makes it difficult for blood to flow through the arteries, often leading to a heart attack or stroke (American Heart Association 2012). Research has established that risk factors for heart trouble include age, obesity, smoking, high blood pressure, and diabetes. Moreover, heart disease remains the most common cause of morbidity and mortality in minority populations and a major cause of racial health disparities (Boykin et al. 2011; Chae et al. 2010; Keenan and Shaw 2011; Krieger and Sidney 1996; Pickering 1999; Winkleby 1999). Research has also found socioeconomic status to be associated with heart health (Boykin et al. 2011; Winkleby et al. 1999). That is, lower income, poor education, and unemployment are related to increased cardiovascular morbidity and mortality (Boykin et al. 2011; Pickering 1999).

Another factor associated with heart disease is racial and ethnic discrimination.

Research has found evidence suggesting that experiences of discrimination have deleterious effects on heart health (Guyll et al. 2001; Lewis et al. 2011). Specifically, several studies show that experiences of acute as well as chronic discrimination based on race or ethnicity adversely affect physical health, including risk for heart disease, above 
and beyond economic disadvantage (Borrell et al. 2006; Friedman et al. 2009; Jackson et al. 1996; Krieger and Sidney 1996; Pascoe and Richman 2009; Williams et al. 1997). Consistent with the literature on stress, the mechanism by which discrimination impacts health suggests that acute or major experiences of discrimination trigger acute episodes of illness while daily or chronic discrimination exacerbate existing disease processes (Bhattacharyya and Steptoe 2007; Williams and Mohammed 2009).

There are also marked regional differences in mortality from heart disease within the United States (Fang et al. 1996). In their examination of the enduring impact of birthplace on mortality from cardiovascular disease among residents of New York City, Fang et al. (1996) found that Southern-born Blacks were at greater risk for heart disease than Northern-born Blacks. Reasons provided for the increased mortality from heart disease among Southern-born Blacks compared to those from other regions included lower socioeconomic status and increased rates of smoking and obesity. The authors also found that African Americans were at significantly greater risk for developing and dying from heart disease than Caribbean Blacks. Compared to African Americans, Caribbean Blacks were of higher socioeconomic status and had lower rates of obesity, factors which help partially explain the differences found in heart disease and mortality outcomes (Fang et al. 1996).

In addition, within the stress process literature, social support (Cohen and Wills 1985; Turner 2010; Uchino et al. 1996) mastery (Caputo 2003; Forbes 2001; Pudrovska et al. 2005; Russek et al. 1990), and self-esteem (Antonucci and Jackson 1983; Gidron et al. 2006; Krol et al. 1994) have all been shown to be negatively associated with coronary heart disease and hypertension (Turner 2010). Further, being married (Eaker et al. 2007; 
Johnson et al. 2000) and religiosity (Hummer et al. 1999; Koenig 2004; Powell et al. 2003) are inversely related to the risk of heart disease.

Racial group identity. Various social factors over the life course influence the racial group identity of Black adults in the United States (Demo and Hughes 1990). Broadly, identities are aspects of the self as well as meanings that people assign to the self and the groups to which they belong (Demo and Hughes 1990; Ida and ChristieMizell 2012). For Black Americans, "identity formation has to do with developing an understanding and acceptance of one's own group in the face of lower status and prestige in society and the presence of stereotypes and racism" (Phinney 1996:144). Thus, development of Black group identity is not only an internal process but is also associated with roles in families, community, and society more broadly. Black group identity is multidimensional and has been most often conceptualized as feelings of closeness to other Blacks and positive Black group evaluation (Demo and Hughes 1990). Closeness to other Blacks captures individuals' levels of feelings or understanding and intimacy with other Blacks (Broman et al. 1988; Demo and Hughes 1990; Ida and Christie-Mizell 2012; Shelton 2008), while Black group evaluation represents an overall appraisal of Blacks as a group, ranging from negative to positive views (Demo and Hughes 1990; Ida and Christie-Mizell 2012).

Social and demographic factors are important for the development of Black racial group identity. Moreover, "individuals vary in the degree to which they identify with their ascribed ethnic group and the extent to which their group identity is salient and significant to them" (Phinney 1996:143-4). Studies suggests that people who are older, less educated, live in the South, and are religiously involved score higher on measures of 
closeness to other Blacks, while those with higer socioeconomic status score lower on closeness to other Blacks, but high on measures of positive Black group evaluation (Broman et al. 1988; Brown et al. 2002; Demo and Hughes; Ida and Christie Mizell 2012). Aside from these factors, research also suggests that the development and importance of racial group identity varies by gender such that racial-ethnic identity is more salient for Black females compared to Black males (Jaret and Reitzes 1999; Phinney 1990). Jaret and Reitzes (1999) also found that for Blacks, racial-ethnic identity varies by social setting such that it matters most in work settings, least at home and is of intermediate concern in neighborhood settings and other public contexts. Black racialethnic identity has also been linked to increased quality of social relationships such as marriage and other intimate relationships (Utsey et al. 2002). Moreover, studies have found Black racial group identity to be associated with risk factors for heart trouble to the extent that there is cultural variation in diet, nutrition, ideas about ideal body image with weight (Caprio et al. 2008; Martin et al. 2001), and the acceptance of smoking (Nguyen et al. 2010). Conversely, other studies have found a link between positive Black racial group identity and helpful psychosocial resources, including increased self-esteem (Carter 1991; Goodstein and Ponterotto 1997; Thomas and Speight 1999; Utsey et al. 2002) and personal mastery (Phinney 1990). Additionally, interpersonal relations with family and social networks have also been found to boost Black racial group identity (Demo and Hughes 1990; Utsey et al. 2002).

Much research has examined linkages between racial group identity and racial discrimination (Branscombe et al. 1999; Chae et al. 2010; Christie Mizell et al. 2008; Clark et al. 1999; LaVeist et al.2001; Shelton and Sellers 2000; Williams 1996). These 
studies suggest that awareness and acknowledgement of racial discrimination is an essential part of healthy Black group identity formation. Specifically, increased recognition of discrimination against one's group is associated with higher levels of group identification (Branscombe et al. 1999; Chae et al. 2010; Cross 1991; LaVeist 2001; Phinney 1996). Most relevant for this study, research has shown that Black racial identity is associated with heart disease. For example, Chae et al. 2010 found negative beliefs about Blacks, i.e. negative Black group evaluation, to be positively associated with cardiovascular disease history.

Ethnic heterogeneity. The visibility of the foreign-born Black population in the United States steadily increased in the last quarter of the $20^{\text {th }}$ century. Between 2001 and 2006, immigration contributed to at least one-fifth growth in the U.S. Black population (Kent 2007). The new wave of Black immigrants that was ushered in by changes in U.S. immigration laws beginning in the 1970s was initially concentrated in certain cities in the United States (e.g., New York and Miami) where communities of Back immigrants, particularly Caribbean Blacks, have traditionally flourished. Caribbean Blacks represent the largest and most established of Black immigrant groups, accounting for slightly more than $4 \%$ of the Black population in the U.S. (Takeuchi et al. 2007).

Despite the diversity that Caribbean Blacks bring to the U.S. Black population, ethnic heterogeneity has less often been studied in sociological research (Griffith et al. 2011; Jackson et al. 2004; Williams and Jackson 2000). Ethnic groups are comprised of people thought to have common cultural traits such as language, nativity, history, traditions, values, and dietary habits that distinguish them from other ethnic groups (Griffith et al. 2011; Smedley and Smedley 2005). Although there are significant 
similarities in the African American and Caribbean Black experiences, such as a shared history of slavery and oppression and continuing struggles with structural and interpersonal discrimination in contemporary America (Ida and Christie-Mizell 2012; Shaw-Taylor 2007; Waters 1999), there are also many important differences. With respect to sociodemographic characteristics, Caribbean Blacks are more likely to be of higher socioeconomic status than African Americans. They also tend to have higher levels of educational attainment, employment, and annual household income than their African American counterparts (Griffith et al. 2011; Ida and Christie-Mizell 2012; Kalmijn 1996; Kent 2007; Williams et al. 2007b). Caribbean Blacks are also more likely to be married than African Americans (Kent 2007).

Further, treatment and actions by the dominant White group and dominant social institutions may exacerbate the structural disadvantage of African Americans relative to Caribbean Blacks. Research shows that White Americans can and do distinguish between foreign-born and American-born Blacks (Griffith et al. 2011; Ida and Christie Mizell 2012, Waters 1991). Due to the differences in socioeconomic attainment, employers may presume that Caribbean Blacks value work and education more than African Americans, despite research to the contrary (Ida and Christie Mizell 2012; Waters 1991). Employers may subsequently view Caribbean Blacks as superior with respect to work ethic, aptitude for learning, and employee compliance and use such notions to justify hiring Caribbean Blacks over African Americans (Ida and Christie-Mizell 2012; Waters 1999; Waters 1991) perpetuating the socioeconomic differences between the two groups. According to the stress process model, these differences in the background, history, and sociodemographic characteristics between Caribbean Blacks and African Americans may 
impact the types of stressors to which each group is exposed, the role psychosocial resources such as racial group identity play in each group's experiences, and subsequent health outcomes. 


\section{CHAPTER III}

\section{HYPOTHESES}

Using the stress process model (Pearlin et al. 1981; Turner 2010), this study examines the relationship between Black racial group identity and history of heart trouble. I test the following hypotheses:

Hypothesis 1: Closeness to other Blacks will decrease the odds of history of heart trouble.

Hypothesis 2: Positive Black group evaluation will decrease the odds of history heart trouble.

I also assess whether the relationship between racial group identity and heart trouble $(\mathrm{H} 1$ and H2) varies by ethnicity. Specifically, I test H1 and H2 for two groups: African Americans and Caribbean Blacks. In the models I develop below, I also control for factors that vary among Blacks living in the United States that prior studies have shown are associated with heart trouble, including gender, age, socioeconomic status, marital status, region of residence, weight, smoking status, experiences of discrimination, and psychosocial resources such as social support, mastery, and self-esteem, and religiosity. 


\section{CHAPTER IV}

\section{DATA AND MEASURES}

\section{Data}

The analyses for this study are based on data from the National Survey of American Life (NSAL). This survey was conducted between February 2001 and March 2003 using a slightly modified version of the Composite International Diagnostic Interview (Jackson et al. 2004a; Jackson et al. 2004b). The primary goal of the NSAL was to gather data on the physical, mental, emotional, structural, and economic conditions of Black Americans (Jackson et al. 2004a). Using an integrated national household probability sampling method, the NSAL interviewed non-institutionalized individuals throughout the United States in urban and rural areas where significant numbers of Black Americans reside. Although the NSAL represents one of the most comprehensive investigations on psychological distress and mental disorders among African Americans $(\mathrm{N}=3,570)$, Caribbean Blacks $(\mathrm{N}=1,621)$, and non-Hispanic Whites $(\mathrm{N}=891)$, it also includes assessments of physical health, religion, and work (see Jackson et al. 2004a; Jackson et al. 2004b for further details on the dataset). This study uses crosssectional data for African American and Caribbean Black adult subsamples. Since nonHispanic Whites were not asked questions regarding Black racial group identity, they are not included in the current study. The analyses presented below consists of 1,588 African Americans and 549 Caribbean Blacks. 


\section{Measures}

Heart trouble. The dependent variable for this study is history of heart trouble. I used a single item where respondents were asked whether a health professional had ever told them they had heart trouble $(1=$ Yes and $0=$ No). Although this is a limited selfreport item of heart disease, prior studies indicate high recall accuracy for cardiovascular health history (Chae et al. 2010; Colditz et al. 1986; Harlow and Linet 1989).

Racial group identity and ethnic heterogeneity. Both racial group identity and ethnicity are key independent variables in the current study. Following Demo and Hughes' (1990) work, I used two dimensions of Black racial group identity: closeness to other Blacks and Black group evaluation. Closeness to other Blacks was measured as an eight-item scale based on respondents' ratings from 1 (not close at all) to 4 (very close) of their closeness in ideas or feelings to: Black people who are poor; religious church-going Black people; young Black people; upper class Black people; working class Black people; older Black people; Black elected officials; and Black doctors, lawyers, and other Black professional people. I summed the responses to these questions and divided by the number of items to range from 1 (low closeness) to 4 (high closeness). The Cronbach's alpha estimate is .87 for African Americans and .85 for Caribbean Blacks. Similarly, Black group evaluation was measured on a six-item scale based on respondents' ratings from 1 (very true) to 4 (not at all true) of how true they thought the following were: Black people are intelligent; are lazy; are hard working; give up easily; are proud of themselves; and are violent. I summed the responses and divided by the number of items and coded to range from 1 (less positive evaluation) to 4 (more positive evaluation). The Cronbach's 
alpha estimate for Black group evaluation was .60 for both African Americans and Caribbean Blacks.

As mentioned above, I categorized respondents who identified as Black but reported no ancestral ties to the Caribbean as African Americans. Moreover, I categorized respondents who self identified as Black and reported ancestral ties to the Caribbean as Caribbean Blacks. In the models developed below, African Americans are coded 1 and compared to Caribbean Blacks.

Control variables. I selected control variables to the extent that prior research has indicated that these factors are associated with heart disease, racial group identity, and ethnicity. With respect to stressor variables, I measured two types of perceived discrimination (Williams et al. 1997; Kessler et al. 1999). First, I included a ten-item measure of day-to-day discrimination, which refers to the perceived frequency of encountering unfair treatment in daily life. The ten items, with responses ranging from 0 (never) to 5 (almost every day) included: treated with less courtesy than other people; treated with less respect than other people; receive poorer service than other people at restaurants or stores; people act like the respondent is not smart; people act as if they are afraid of the respondent; people act like the respondent is dishonest; people act as if they are better than the respondent; called names or insulted; threatened or harassed; and followed in stores. I summed the 10 items and divided by the number of items to range from 0 (lower discrimination) to 5 (higher discrimination). The Cronbach's alpha estimate for daily discrimination was above .85 for both African Americans and Caribbean Blacks. 
Major lifetime discrimination measured respondents' perceived level of exposure to unfair treatment that has affected their life chances. In this study, I used a count based on respondents' responses $(1=$ Yes and $0=$ No $)$ to the following nine items: unfairly fired; not hired for unfair reasons; unfairly denied promotion; unfairly treated/abused by police; discouraged unfairly by a teacher from continuing education; prevented unfairly from moving into a neighborhood because the landlord or realtor refused to sell a house or apartment; life was made difficult by neighbors; unfairly denied a loan; and received service from someone such as a plumber or car mechanic that was worse than what others get. Summing the major discrimination variable provided a scale ranging from 0 (low exposure to major discrimination) to 9 (high exposure to major discrimination).

Other variables measuring risk factors for heart disease included weight and smoking. I measured weight as body mass index (BMI). I created a series of dummy variables to distinguish those respondents who were underweight (BMI less than 18.5), a healthy weight (BMI of 18.5 to 24.9), overweight (BMI 25.0 to 29.9), and obese (BMI greater than 30.0). In the regression models presented below, I compared those who are obese (1=Yes) to all other weight categories. This division is supported by preliminary sensitivity analyses showing that differences in heart trouble are between those who are obese and all other BMI categories. These sensitivity analyses are not presented for the sake of brevity, but are available upon request. Also included is a measure for smoking status, coded $1=$ Yes for respondents that currently smoke compared to those who are former smokers and those who have never smoked.

I also included psychosocial resources that are associated with heart disease and ethnicity. These measures include social support, mastery, self-esteem, and religiosity. 
For social support, I used a modified version of the Received Emotional Support Scale developed by the Fetzer Institute and National Institute on Aging Working Group (1999). This particular scale measures perceived social support received from family members. The three-item scale asked respondents to report from 1 (very often) to 4 (never) how regularly family members: make him/her feel loved and cared for; listen to him/her talk about his/her private problems and concerns; and express interest and concern in his/her well-being. I coded, summed and divided by the number of items to range from 1(low social support) to 4 (high social support). The Cronbach's alpha for this measure of social support was .76 for African Americans and .73 for Caribbean Blacks.

I measured mastery using Pearlin’s Mastery Scale (1989), a seven-item scale in which respondents were asked their level of agreement from 1 (strongly agree) to 4 (strongly disagree) with the following items: There is really no way I can solve some of the problems I have; Sometimes I feel that I'm being pushed around in life; I have little control over the things that happen to me; I can do just about anything I really set my mind to; I often feel helpless in dealing with the problems of life; What happens to me in the future mostly depends on me; and There is little I can do to change many of the important things in my life. I summed and coded the responses so that higher scores reflected higher levels of mastery or a greater sense of control in life, ranging from 1 (low mastery) to 4 (high mastery). The Cronbach's alpha estimate for mastery was .72 for both the African American and Caribbean Black subsamples.

I measured self-esteem using the well-known and valid 10-item Rosenberg Selfesteem Scale (Rosenberg 1965). The scale contains items asking respondents to rate their level of agreement from 1 (strongly agree) to 4 (strongly disagree) on the following 
items: I am person of worth/equal to others; I have a number of good qualities; I am a failure; I do things as well as others; I don't have much to be proud of; I take a positive attitude toward self; I am satisfied with self; I want more self-respect; I sometimes feel useless; and I sometimes think I am no good. Each item was coded to reflect high selfesteem. After summing each item and dividing by ten, the result is a scale that ranges from 1 (lower self-esteem) to 4 (higher self-esteem). The alpha reliability is .77 for African Americans and .79 for Caribbean Blacks.

Finally I measured religiosity, which includes both a single item measuring the frequency of attending religious services—ranging from 1(low attendance) to 5 (high attendance) as well as a five-item scale measuring the importance of religion or spirituality in life. This scale asked respondents to rate the following items from 1(not important at all) to 4 (very important): the importance of religion in the home growing up; parents taking children to religious services; religion in the respondent's life; spirituality in the respondent's life, and prayer in dealing with stressful situations. I summed the responses and coded them to range from 1(low importance) to 4 (high importance). The Cronbach's alpha estimate for the importance of religion was .71 for African Americans and .70 for Caribbean Blacks.

Demographic and socioeconomic variables included gender, with female coded 1 and compared to males. I measured age in years and restricted the sample to those who were 40 years of age and older, since the research indicates diagnoses of heart trouble rarely happen before middle adulthood. Further, educational attainment was measured in years, and household income measured in dollars and logged for the regressions model below to prompt heterogeneity of error variance. Employment status was coded 1 for full- 
time employment and compared to those who were working part-time, unemployed and not in the labor force. I also included marital status, which compared those who were married or cohabitating $(1=$ Yes $)$ with those who were single and divorced, separated, or widowed; as well as a region variable comparing respondents from the South to those in the Northeast, Midwest, and West. 


\section{CHAPTER V}

\section{ANALYTIC STRATEGY}

The primary purpose of this study is to examine the relationship between Black racial group identity and heart trouble. The study also assesses whether this relationship is moderated by ethnicity. The analytic strategy for the study was accomplished in three steps. First, I generated descriptive statistics for all study variables by comparing means and proportions for African Americans and Caribbean Blacks. Second, I conducted multivariate analyses using logistic regression to establish the relationship between heart trouble and variables of interest in seven models. The first model was a baseline establishing the direct effects of demographic and socioeconomic variables on history of heart trouble. Next, guided by the stress process model (Pearlin et al. 1981; Turner 2010), I built on the first model by adding stressors: daily and major discrimination, obesity, and smoking. Following this step, I added social and personal resources to the model, including measures of social support, mastery, self-esteem, and religiosity. The fourth through sixth models included demographic and socioeconomic variables and stressors, to which I added the two Black racial group identity measures separately and then together. Thus, the fourth model includes only closeness to other Blacks; the fifth includes only Black group evaluation; and the sixth includes both closeness to other Blacks and Black group evaluation. The seventh model includes all variables: demographic and socioeconomic, stressors, social and personal resources, and the two measures of racial group identity. These seven models together help in establishing the 
separate main effects of the variables of interest as well as how they operate together to shape heart trouble. Finally, using interactions, I tested whether the impact of closeness to other Blacks and Black group evaluation varies for African Americans compared to Caribbean Blacks. The analyses were weighted to ensure representativeness and to correct for the NSAL's complex sampling design (Ida and Christie Mizell 2012). 


\section{CHAPTER VI}

\section{RESULTS}

\section{Descriptive and Bivariate Findings}

Table 1 presents results of descriptive and bivariate statistics for African Americans and Caribbean Blacks. African Americans report significantly higher rates of heart trouble compared to Caribbean Blacks (12.03 percent vs. 8.01 percent). With respect to Black racial group identity, African Americans express significantly higher levels of closeness to other Blacks than Caribbean Blacks (3.29 vs. 3.15). However, there is no significant difference in levels of Black group evaluation between the two groups (3.18 for African Americans and 3.19 for Caribbean Blacks). Interestingly, closeness to other Blacks is positively and significantly associated with heart trouble for African Americans but not associated with heart trouble for Caribbean Blacks. Positive Black group evaluation is negatively associated with history of heart trouble for African Americans, but not for Caribbean Blacks. 
Table 1: Weighted Means and Proportions of a National Survey of American Life Sample of African Americans and Caribbean Blacks ( $\mathrm{N}=\mathbf{2 , 1 3 7 )}$.

\begin{tabular}{|c|c|c|c|c|c|c|c|}
\hline \multirow[b]{2}{*}{ Variables } & \multicolumn{3}{|c|}{ African Americans } & \multicolumn{4}{|c|}{ Caribbean Blacks } \\
\hline & $\begin{array}{c}\text { Mean/ } \\
\text { Percent }\end{array}$ & SD & $\begin{array}{c}\text { Correlation } \\
\text { with Heart } \\
\text { Trouble }\end{array}$ & $\begin{array}{c}\text { Mean/ } \\
\text { Percent }\end{array}$ & SD & $\begin{array}{c}\text { Correlation } \\
\text { with Heart } \\
\text { Trouble }\end{array}$ & \\
\hline History of Heart Trouble $(1=\text { Yes })^{a}$ & $12.03 \%$ & -- & -- & $8.01 \%$ & -- & -- & B \\
\hline \multicolumn{8}{|l|}{ Demographics and Socioeconomic Status } \\
\hline Female (1=Yes) & $63.66 \%$ & -- & .01 & $62.11 \%$ & -- & -.05 & \\
\hline Age $(\geq 40)$ & 54.68 & 11.80 & $.21^{* * * *}$ & 53.25 & 11.30 & $.09^{*}$ & $\mathrm{C}$ \\
\hline Education (Years) & 12.17 & 2.81 & $-.11^{* * * *}$ & 12.88 & 3.14 & .03 & A \\
\hline Household Income (Dollars) & 33133 & 30759 & $-.09^{* * * *}$ & 43858 & 34957 & -.06 & A \\
\hline Employed (1=Yes) & $58.56 \%$ & -- & $-.20^{* * * *}$ & $70.13 \%$ & - & $-.22^{* * * * *}$ & A \\
\hline Married/Cohabitating (1=Yes) & $36.59 \%$ & -- & -.03 & $48.45 \%$ & -- & -.03 & A \\
\hline South (1=Yes) & $64.17 \%$ & -- & .02 & $28.96 \%$ & -- & -.03 & A \\
\hline \multicolumn{8}{|l|}{$\underline{\text { Risk Factors \& Stressors }}$} \\
\hline Obese (BMI > 30.0) & $37.59 \%$ & -- & .04 & $24.77 \%$ & -- & $.09^{*}$ & A \\
\hline Currently Smoke (1=Yes) & $29.85 \%$ & -- & -.03 & $12.75 \%$ & -- & .01 & A \\
\hline Day-to-Day Discrimination: 0 (low) to 5 (high) & 1.10 & .87 & -.03 & 1.04 & .84 & $.19^{* * * *}$ & \\
\hline Major Discrimination: 0 (low) to 9 (high) & 1.45 & 1.71 & .01 & 1.24 & 1.59 & $.17^{* * * *}$ & B \\
\hline \multicolumn{8}{|l|}{ Social \& Personal Resources } \\
\hline Social Support: 1 (low) to 4 (high) & 3.21 & .72 & .02 & 3.20 & .68 & -.05 & \\
\hline Mastery: 1 (low) to 4 (high) & 3.26 & .61 & $-.13^{* * *}$ & 3.15 & .60 & -.02 & A \\
\hline Self Esteem 1 (low) to 4 (high) & 3.59 & .43 & $-.08^{\text {***** }}$ & 3.65 & .39 & -.02 & B \\
\hline Importance of Religion: 1 (low) to 4 (high) & 3.84 & .31 & $.07^{* *}$ & 3.81 & .36 & -.02 & $\mathrm{C}$ \\
\hline Religious Attendance: 1 (low) to 5 (high) & 3.18 & 1.11 & .02 & 3.16 & 1.14 & -.04 & \\
\hline \multicolumn{8}{|l|}{ Racial Group Identity } \\
\hline Closeness to Other Blacks: 1(low) to 4(high) ${ }^{b}$ & 3.29 & .54 & $.06^{*}$ & 3.15 & .54 & -.02 & A \\
\hline Black Group Evaluation: 1(low) to 4 (high) ${ }^{\mathrm{c}}$ & 3.18 & .47 & $-.10^{\text {\%का }}$ & 3.19 & .49 & -.01 & \\
\hline
\end{tabular}

${ }^{\text {a }}$ History of heart disease is measure by a single item asking respondents whether a professional had told them they had heart trouble.

${ }^{\mathbf{b}}$ Closeness to other blacks is measured as an 8-item scale, coded to range from 1 (low closeness) to 4 (high closeness).

${ }^{\mathbf{c}}$ Black group evaluation is measured as a 6-item scale and coded to range from 1 (less positive) to 4 (more positive).

Note: Letters denote significant differences in means and proportions between African Americans and Caribbean Blacks, where $\mathrm{p}<.001=\mathrm{A} ; \mathrm{p}<.01=\mathrm{B} ; \mathrm{p}<.05=\mathrm{C}$. 
Compared to Caribbean Blacks, African Americans are older (54.68 vs. 53.25), less likely to be employed (58.56 percent vs. 70.13 percent), have attained fewer years of education (12.17 vs. 12.88), have less household income ( $\$ 33,133$ vs. $\$ 43,858)$, and are less likely to be married ( 36.59 percent vs. 48.45 percent). The bivariate associations reveal a positive relationship between age and heart trouble for both groups as well as a negative correlation between education and heart problems for African Americans but not for Caribbean Blacks. Further, while household income is negatively associated with history of heart trouble for African Americans, employment is negatively associated with history of heart trouble for both African Americans and Caribbean Blacks. Further, there is a comparable concentration of women between African Americans (63.66 percent) and Caribbean Blacks (62.11 percent). However, more African Americans reside in the Southern region of the United States than Caribbean Blacks (64.17 percent vs. 28.96 percent).

With respect to stressors, there is no significant difference in levels of day-to-day discrimination between African Americans and Caribbean Blacks (1.10 and 1.04, respectively). However, African Americans (1.45) experience significantly higher incidents of major discrimination compared to Caribbean Blacks (1.24). African Americans are also more likely to be obese than Caribbean Blacks (37.59 percent vs. 24.77 percent). Further, African Americans are significantly more likely to smoke compared to Caribbean Blacks (29.85 percent vs. 12.75 percent). While neither of the discrimination measures bears a significant relationship with heart trouble for African Americans, both day-to-day discrimination and major discrimination are positively and 
significantly correlated with history of heart trouble for Caribbean Blacks. Being obese is positively associated with history of heart trouble for Caribbean Blacks only.

Regarding social and personal resources, there is no significant difference between African Americans (3.21) and Caribbean Blacks (3.20) with respect to levels of social support. However, African Americans report significantly higher levels of mastery (3.26 vs. 3.15), while Caribbean Blacks report significantly higher levels of self-esteem (3.65 vs. 3.59). Also, while levels of religious attendance are similar for African Americans (1.11) and Caribbean Blacks (1.14), African Americans report significantly higher levels of the importance religion and spirituality plays in their lives (3.84 vs. 3.81). Mastery is negatively associated with history of heart trouble for African Americans only. Similarly, there is a negative correlation between self-esteem and heart trouble for African Americans but not Caribbean Blacks. Moreover, the importance of religion is positively associated with history of heart trouble for African Americans only.

\section{Multivariate Findings}

The multivariate results are presented in Table 2. Recalling that the first step in my model building was to establish a baseline of the direct effects of demographic and socioeconomic variables on history of heart trouble, Model 1 shows that age and employment are both associated with history of heart trouble. Age is associated with significantly increased odds of heart trouble (logit $=2.00$, odds $=7.39$ ), while being employed is associated with significantly decreased odds of heart trouble $(\operatorname{logit}=-.63$, odds $=.53$ ). A one-year increase in age increases the odds of heart trouble by $639 \%$, 
Table 2: Logistic Regression of Heart Trouble on Selected Variables National Survey of American Life $(\mathrm{N}=2,137){ }^{\text {a }}$

\begin{tabular}{|c|c|c|c|c|c|c|c|c|c|c|c|c|c|c|}
\hline & \multicolumn{2}{|c|}{ Model 1} & \multicolumn{2}{|c|}{ Model 2} & \multicolumn{2}{|c|}{ Model 3} & \multicolumn{2}{|c|}{ Model 4} & \multicolumn{2}{|c|}{ Model 5} & \multicolumn{2}{|c|}{ Model 6} & \multicolumn{2}{|c|}{ Model 7} \\
\hline & Logit & Odds & Logit & Odds & Logit & Odds & Logit & Odds & Logit & Odds & Logit & Odds & Logit & Odds \\
\hline \multicolumn{15}{|l|}{ Demographics and Socioeconomic Status } \\
\hline African Americans (1=Yes) & -.38 & .68 & -.52 & .60 & -.48 & .62 & -.52 & .60 & -.56 & .57 & -.57 & .56 & -.52 & .59 \\
\hline Female (1=Yes) & .12 & 1.12 & .25 & 1.28 & .14 & 1.15 & .24 & 1.27 & .19 & 1.21 & .17 & 1.18 & .09 & 1.10 \\
\hline Age (logged years) & $2.00^{* * * *}$ & 7.39 & $2.63^{* * * *}$ & 13.84 & $2.69^{* * * *}$ & 14.77 & $2.59^{* * * *}$ & 13.31 & $2.63^{* * *}$ & 13.81 & $2.57^{* * *}$ & 13.09 & $2.62^{* * *}$ & 13.75 \\
\hline Education (Years) & -.02 & .98 & -.02 & .98 & .00 & 1.00 & -.02 & .98 & .00 & 1.00 & .00 & 1.01 & .02 & 1.02 \\
\hline Household Income (Logged Dollars) & -.05 & .95 & -.06 & .94 & -.05 & .96 & -.06 & .94 & -.04 & .96 & -.04 & .96 & -.03 & .97 \\
\hline Employed & $-.63^{*}$ & .53 & $-.60^{*}$ & .55 & $-.53 *$ & .59 & $-.61^{*}$ & .54 & $-.63^{* *}$ & .53 & $-.64^{* * *}$ & .53 & $-.58^{*}$ & .56 \\
\hline Married/Cohabitating (1=Yes) & .10 & 1.11 & .17 & 1.19 & .17 & 1.19 & .16 & 1.17 & .14 & 1.15 & .11 & 1.12 & .11 & 1.12 \\
\hline South (1=Yes) & .12 & 1.12 & .24 & 1.27 & .20 & 1.22 & .21 & 1.23 & .28 & 1.33 & .24 & 1.27 & .21 & 1.23 \\
\hline \multicolumn{15}{|l|}{$\underline{\text { Risk Factors \& Stressors }}$} \\
\hline Obese (BMI > 30.0) & & & $.47^{*}$ & 1.59 & $.49^{*}$ & 1.63 & $.46^{*}$ & 1.59 & $.43^{*}$ & 1.54 & $.42^{*}$ & 1.52 & $.44^{*}$ & 1.56 \\
\hline Currently Smoke (1=Yes) & & & .11 & 1.12 & .11 & 1.12 & .11 & 1.11 & .14 & 1.15 & .14 & 1.15 & .13 & 1.14 \\
\hline Day-to-Day Discrimination: 0 (low) to 5 (high) & & & $.21^{*}$ & 1.23 & .16 & 1.18 & $.22^{*}$ & 1.25 & .14 & 1.15 & .15 & 1.16 & .12 & 1.13 \\
\hline Major Discrimination: 0 (low) to 9 (high) & & & $.12^{*}$ & 1.12 & $.12^{*}$ & 1.13 & $.12 *$ & 1.12 & $.15^{* * *}$ & 1.16 & $.15^{* *}$ & 1.16 & $.15^{* *}$ & 1.16 \\
\hline \multicolumn{15}{|l|}{ Social \& Personal Resources } \\
\hline Social Support: 1 (low) to 4 (high) & & & & & .07 & 1.08 & & & & & & & .07 & 1.07 \\
\hline Mastery: 1 (low) to 4 (high) & & & & & -.31 & .74 & & & & & & & -.29 & .75 \\
\hline Self Esteem 1 (low) to 4 (high) & & & & & -.08 & .92 & & & & & & & .04 & 1.04 \\
\hline Importance of Religion: 1 (low) to 4 (high) & & & & & .66 & 1.94 & & & & & & & .54 & 1.71 \\
\hline Religious Attendance: 1 (low) to 5 (high) & & & & & .01 & 1.01 & & & & & & & -.01 & .99 \\
\hline \multicolumn{15}{|l|}{ Racial Group Identity } \\
\hline Closeness to Other Blacks: 1 (low) to 4 (high) ${ }^{b}$ & & & & & & & .28 & 1.32 & & & $.40^{*}$ & 1.49 & $.36^{*}$ & 1.43 \\
\hline Black Group Evaluation: 1 (low) to 4 (high) ${ }^{\mathrm{c}}$ & & & & & & & & & $-.88^{* * * *}$ & .41 & $-.95^{* * * *}$ & .39 & $-.90^{* * *}$ & .41 \\
\hline
\end{tabular}


while being employed decreases the odds of heart trouble by $47 \%$. Model 1 also shows no significant difference in odds of heart trouble by African American ethnicity. Having established the direct effects of demographic and socioeconomic variables, Model 2 of Table 2 adds stressors to determine the impact of these variables on heart trouble. Model 2 shows that both day-to-day and major discrimination have significant impacts on history of heart trouble. Day-to-day discrimination increases the odds of heart trouble by $23 \%(\operatorname{logit}=.21$, odds $=1.23)$, while major discrimination increases the odds of heart trouble by $12 \%$ (logit $=.12$, odds $=1.12$ ). Further, being obese, compared to other weight categories, increases the odds of heart trouble by $59 \%$ $(\operatorname{logit}=.47$, odds $=1.59)$. Being a current smoker is not significantly associated with the odds of heart trouble. Age still significantly increases the odds of heart trouble in Model 2 ; however, the increase in the odds of heart trouble has nearly doubled from the previous model (odds $=7.39$ for Model 1 versus odds = 13.84 for Model 2). Similarly, being employed remains significant in Model 2, decreasing the odds of heart trouble by $45 \%$.

The third model in Table 2 adds social and personal resources. Model 3 shows that none of the resources: social support, mastery, self-esteem, the importance of religion, and religious attendance, are significantly associated with the odds of history of heart trouble. However, in the presence of personal and social resources, major discrimination remains positively and significantly associated with the odds of heart trouble, but day-to-day discrimination is no longer significantly associated with the odds of heart trouble. An increase in major discrimination is associated with a $12 \%$ increase in the odds of heart trouble $((\operatorname{logit}=.12$, odds $=1.12)$. Also, obesity remains significantly and positively associated with the odds of heart trouble (logit $=.44$, odds $=1.56)$ in the 
presence of social and personal resources. All other variables that were significant in the prior model remain significant in Model 3.

Model 4 includes demographic and socioeconomic variables, stressors, and one dimension of racial group identity: closeness to other Blacks. The model shows that closeness to other Blacks is not significantly associated with the odds of heart trouble. However, similar to Model 2, both day-to-day and major discrimination are significantly associated with the odds of heart trouble in Model 4. Day-to-day discrimination increases the odds of heart trouble by $25 \%(\operatorname{logit}=.22$, odds $=1.25)$, while major discrimination increases the odds of heart trouble by $12 \%(\operatorname{logit}=.12$, odds $=1.12)$. All other variables that were significant in prior models remain significant in Model 4.

Model 5 includes demographic and socioeconomic status, stressors, and the other dimension of racial group identity: Black group evaluation. Unlike the case for closeness to other Blacks in Model 4, this model shows that Black group evaluation is significantly associated with the odds of heart trouble. Positive Black group evaluation decreases the odds of heart trouble by $59 \%(\operatorname{logit}=-.88$, odds $=.41)$. Similar to Model 2 , the presence of Black group evaluation, major discrimination remains positively and significantly associated with the odds of heart trouble, but day-to-day discrimination is not significantly associated with the odds of heart trouble. An increase in major discrimination is associated with a $16 \%$ increase in the odds of heart trouble $((\operatorname{logit}=.15$, odds $=1.16$ ). Otherwise, all other variables that were significant in prior models remain significant in Model 5.

Model 6 includes demographic and socioeconomic status, stressors, and the two measures of racial group identity, closeness to other Blacks and Black group evaluation. 
Black group evaluation remains significantly associated with the odds of history of heart trouble. Positive Black group evaluation decreases the odds of heart trouble by $61 \%$ (logit $=-.95$, odds $=.39$ ). Model 6 also reveals that in the presence of Black group evaluation, closeness to other Blacks is significantly associated with the odds of heart trouble. An increase in closeness to other Blacks is associated with a $49 \%$ increase in odds of heart trouble $((\operatorname{logit}=.40$, odds $=1.49)$. Together, the results from models four through six showing that closeness to other Blacks is significant in the presence (but not otherwise) of positive Black group evaluation represents a "suppressor effect," which occurs when the impact of one variable on the dependent variable is clarified when another independent variable is entered into the model (Christie-Mizell and Erickson 2007; Cohen and Cohen 2003). Also, in the presence of the two measures of Black racial group identity, major discrimination is positively and significantly associated with the odds of heart trouble, but day-to-day discrimination is not significantly associated with the odds of heart trouble. Similar to Model 5, an increase in major discrimination is associated with a $16 \%$ increase in the odds of heart trouble (logit $=.15$, odds $=1.16)$. Otherwise, all other variables that were significant in prior models remain significant in Model 5.

In the final model of Table 2, Model 7 includes all study variables. Both dimensions of Black racial group identity remain significantly associated with history of heart trouble. While positive Black group evaluation decreases the odds of heart trouble by $59 \%$ (logit $=-.90$, odds $=.41)$, closeness to other Blacks increases the odds of heart trouble by $43 \%(\operatorname{logit}=.36$, odds $=1.43)$. Consistent with Model 6 , Model 7 shows that major discrimination remains positively and significantly associated with history of heart trouble. An increase in major discrimination is associated with a $16 \%$ increase in the odds 
of heart trouble $(\operatorname{logit}=.15$, odds $=1.16)$. All other variables that were significant in prior models, including obesity, being employed, and age remain significant in this final model. 
Table 3: Logistic Regression of Heart Trouble on Selected Variables National Survev of American Life (N=2,137). ${ }^{a}$

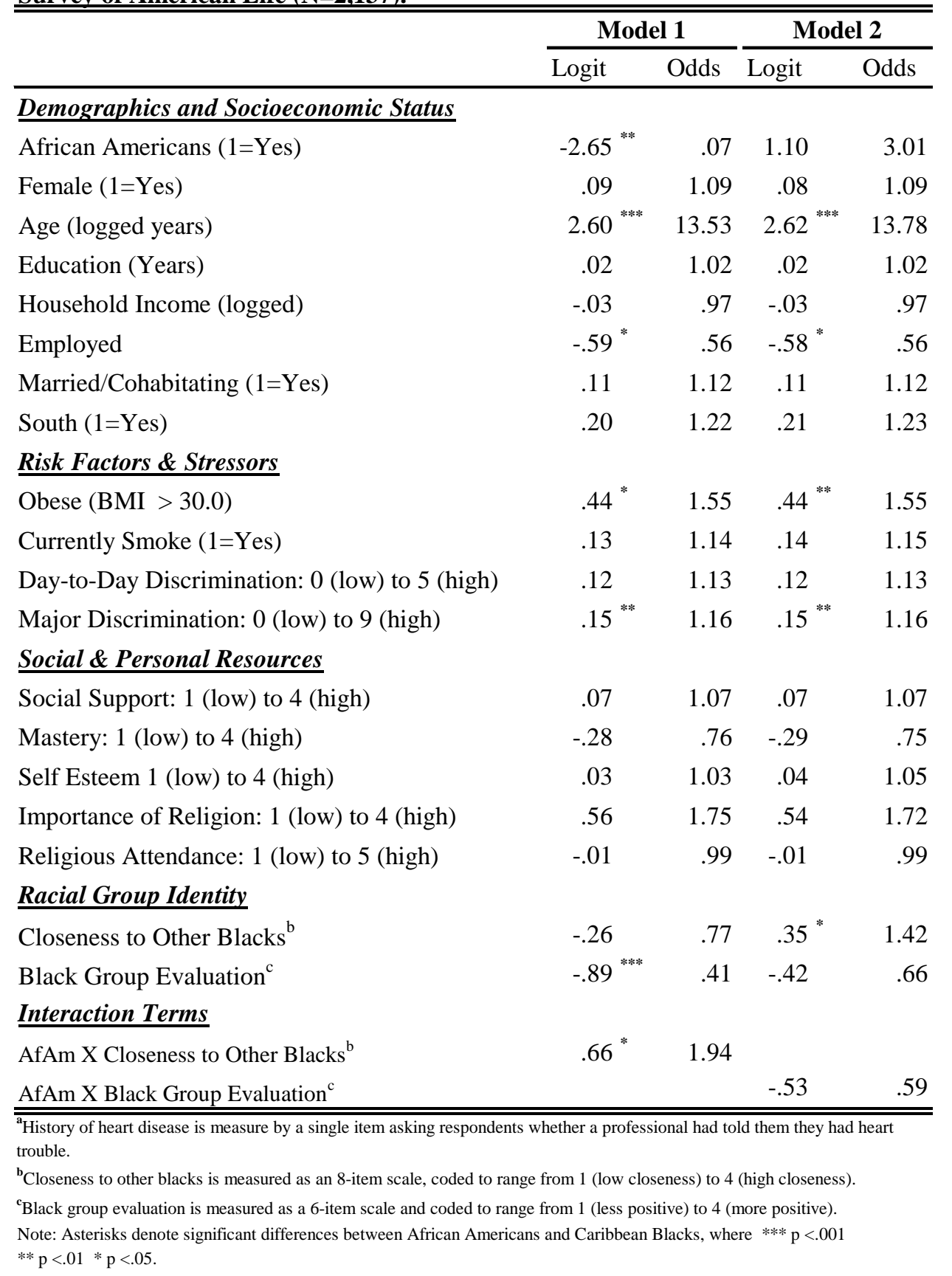


Table 3 presents results of the interactions between the two dimensions of racial group identity and ethnicity in predicting history of heart trouble. Model 1 presents the interaction between closeness to other Blacks and ethnicity and Model 2 presents the interaction between Black group evaluation and ethnicity. Ethnicity moderates the effects of closeness to other Blacks on history of heart trouble (Model 1). Figure 1, which graphically displays the interaction, shows that at low levels of closeness to other Blacks there is little difference between African Americans and Caribbean Blacks in the probability of heart trouble. However, as closeness to other Blacks increases, there is an increasing trajectory for African Americans and a decreasing trajectory for Caribbean Blacks such that at high levels of closeness to other Blacks, there is a significant difference in the probability of history of heart trouble for African Americans compared to Caribbean Blacks. Model 2 of Table 3 shows no significant interaction between Black group evaluation and ethnicity. 


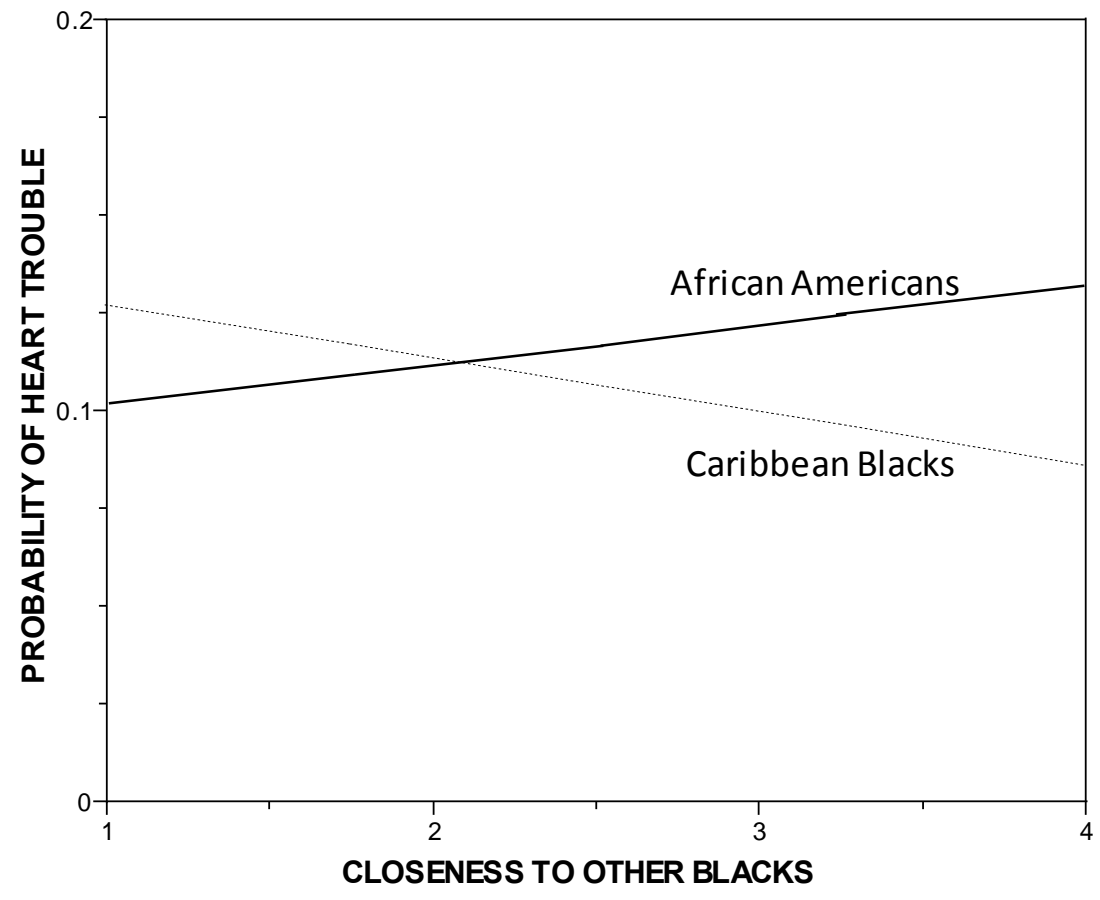

Figure 1. Interaction between Closeness to Other Blacks and Ethnicity. 


\section{CHAPTER VII}

\section{DISCUSSION AND CONCLUSIONS}

Using the stress process model, I examined how racial group identity shapes history of heart trouble among Black Americans. I further explored ethnic heterogeneity by examining whether the relationship between identity and heart trouble varies for African Americans compared to Caribbean Blacks. Contrary to my first hypothesis, the main effects results indicate that rather than decreasing the odds of history of heart trouble, increased closeness to other Blacks increased the odds of history of heart trouble. However, consistent with my second hypothesis, the results showed that increased positive Black group evaluation decreased the odds of history of heart trouble. The results from Table 2, Models 4-6 help clarify these unexpected findings. As mentioned above, together, these models reveal a suppressor effect of positive Black group evaluation on closeness to other Blacks. This pattern of statistical suppression is explained by the fact that closeness to other Blacks is higher among those with higher positive group evaluation $(\mathrm{r}=.16, \mathrm{p}<.0001$; correlations available upon request). Therefore, the inclusion of positive Black group evaluation in the model produces a significant, positive relationship for closeness to other Blacks in the prediction of heart trouble (cf. ChristieMizell and Erickson 2007).

Notwithstanding suppression, recall that the interaction effects show that closeness to other Blacks only represents a liability or positive association for African Americans. For Caribbean Blacks, closeness to other Blacks decreases the probability of 
heart trouble and is the type of helpful psychosocial resource outlined by the stress process model. Because the status of African Americans living in the United States is more tenuous than that of Caribbean Blacks, closeness to other Blacks as a psychosocial resource may simply be a more taxing proposition and may heighten the conditions that are related to heart trouble for African Americans. Conversely, positive Black group evaluation is a psychosocial resource that buffers both African Americans and Caribbean Blacks in the way that the stress process model outlines.

The mechanisms by which black group evaluation lowers risk for heart disease are still being explored. Some researchers have found negative black evaluation to be directly associated with cardiovascular disease such that the more internalized negative racial group attitudes Blacks had, the higher their risk of cardiovascular disease (Chae et al. 2010). In their suggestions for future research and policy considerations, Chae et al. (2010) recommend interventions that promote positive racial attitudes and beliefs. This current study provides additional evidence that fostering positive black group evaluation could help lower the risk for heart disease. Moreover, researchers examining the relationship between positivity and heart health using constructs like optimism have found that people who have more positive attitudes engage in more healthy behaviors such as physical activity, healthful eating, and adequate sleep. In addition, such people tend to have physiological functioning linked to lowered risk of heart disease such as lower blood pressure and healthier lipid profiles (Boehm and Kubzansky 2012). Together these findings with respect to the two dimensions of Black racial identity are consistent with previous research suggesting that it is not only how identified individuals are with a group (i.e. closeness to other Blacks) but the meanings they place on what it means to be 
a member of that group (i.e. black group evaluation) that protects individuals from negative consequences (Sellers and Shelton 2003).

There are two notable contributions of this study to understanding the history of heart trouble for Black Americans. First, although gaining more attention, ethnic heterogeneity among Black Americans remains relatively neglected in much of the health research (Griffith et al. 2011; Ida and Christie-Mizell 2012; Williams and Jackson 2000). Had I not considered ethnicity, I would have wrongly concluded that a positive relationship exists between closeness to other Blacks and heart trouble for all Blacks living in the United States. Instead, my consideration of ethnicity, not just race, revealed a more nuanced finding, in which African Americans face greater risk as a result of closeness to other Blacks compared to Caribbean Blacks. Second, the utilization of the stress process model to explain physical health has not been fully exploited in the research literature and its use has proven fruitful in the current study. Particularly useful for this study is that the stress process is not limited to only outlining the unequal distribution of conventional stressors and psychosocial resources in the population (Turner 2010). This fact drove my focus on ethnicity and to the finding that the impact of racial group identity on history of heart trouble varies for African Americans and Caribbean Blacks.

This study, however, is not without limitations. First, since the NSAL is crosssectional, it is difficult to identify causal associations among the factors examined. Specifically, using cross-sectional data to examine a construct such as racial group identity, which is dynamic and changes over time, is limiting (Phinney 1996). Second, although this study examined two dimensions of racial group identity, additional 
dimensions may provide a more complete picture of differences within the U.S. Black population. That is, measures of closeness or group evaluation might be better supplemented with other group identity measures, such as those that combine dimensions of group optimism or knowledge of group history. Broadening conceptualizations of racial group identity is important because recent research suggests that the manner in which Black race and ethnicity are conceptualized and measured influences health outcomes (Broman et al. 2010). Moreover, other research shows that, because of structural positioning some groups, (e.g., Caribbean Blacks) have more latitude in constructing attitudes about racial identity (Waters 1999). "Different self-identifications of race-ethnicity result in different conclusions regarding health status outcomes among African Americans and Caribbean Black populations, even when controlling for social, economic and demographic differences" (Broman et al. 2010: 88). Finally, this study uses a single self-report item that requires the input of a health professional to measure history of heart trouble. However, as mentioned above, due to the salient impact having a heart condition diagnosed has on individuals, the level of accuracy for recalling heart health history is high (Chae et al. 2010).

Despite these limitations, this study has the advantage of using a nationally representative dataset with a sample large enough to allow exploration of ethnic heterogeneity in the U.S. Black population. This diversity among Black Americans is especially important if current trends in U.S. Black immigration continue. Several studies reveal that the longer Caribbean Blacks or any Black immigrant groups stay in the U.S., the more likely they are to lose their health advantage and converge to the health profiles of U.S. born African Americans (Griffith et al. 2011; Read and Emerson 2005; Singh and 
Siahpush 2002). Although Black-White disparities in heart disease are well known and documented in the research literature, these apparent intra-racial differences may actually obscure larger variations within the Black population (Fang et al. 1996). The growing number of Black immigrants entering the United States from the Caribbean and elsewhere is and will continue to change the demographic, cultural, and health landscape of the U.S. Black population. Future research should further examine the heterogeneity in race and ethnicity in order to illuminate how social and cultural differences among African Americans, Caribbean Blacks as well as other Black immigrant groups contribute to racial health disparities in the U.S in order to better inform the development and implementation of appropriate social and public policies and interventions. 


\section{REFERENCES}

American Heart Association. 2012. What is Cardiovascular Disease (Heart Disease)? Retrieved on March 27, 2012 (http://www.heart.org/HEARTORG/Caregiver/ Resources/WhatisCardiovascularDisease/What-is-CardiovascularDisease_UCM _301852_Article.jsp\#.T4CVDXjyHAM).

Bhattacharyya, Mimi R. and Andrew Steptoe, A. 2007. "Emotional Triggers of Acute Coronary Syndromes: Strength of Evidence, Biological Processes, and Clinical Implications." Progress in Cardiovascular Diseases 49(5):353-365.

Boehm, Julia K. and Laura D. Kubzansky. 2012. "The Heart's Content: The Association Between Positive Psychological Well-Being and Cardiovascular Health."

Psychological Bulletin. Advance online publication. doi: 10.1037/a0027448

Borrell, Luisa N. Catarina I. Kiefe, David R. Williams, Ana V. Diez-Roux, and Penny Gordon-Larsen. 2006. "Self-Reported Health, Perceived Discrimination, and Skin Color in African Americans in the CARDI Study." Social Science \& Medicine 63:1415-27.

Boykin, Shawn, Ana V. Diez-Roux, Mercedes Carnethon, Saudi Shrager, Hanyu Ni, and Melicia Whitt-Glover. 2011. "Racial/Ethnic Heterogeneity in the Socioeconomic Patterning of CVD Risk Factors in the United States: The Multi-Ethnic Study of Atherosclerosis." Journal of Health Care for the Poor and Underserved 22(1):111-27.

Branscombe, Nyla R., Michael T. Schmitt, and Richard D. Harvey. 1999. "Perceiving Pervasive Discrimination among African Americans: Implications for Group Identification and Well-Being." Journal of Personality and Social Psychology 77(1):135-149.

Broman, Clifford, Harold Neighbors, and James S. Jackson. 1988. "Racial Group Identification Among Black Adults.” Social Forces 67(1):146-158.

Broman, Clifford L., Myriam Torres, Renee B. Canady, Harold W. Neighbors, and James S. Jackson. 2010. "Race and Ethnic Self-Identification Influences on Physical and Mental Health Statuses Among Blacks.” Race and Social Problems 2:81-91.

Brotman, Daniel J., Sherita H. Golden, and Ilan S. Wittstein. 2007. "The Cardiovascular Toll of Stress." Lancet 370(9592):1089-1100.

Brown, Tony N., Sherrill L. Sellers, and John P. Gomez. 2002. "The Relationship Between Internalization and Self-Esteem among Black Adults.” Sociological Focus 35(1):55-71. 
Caprio, Sonia, Stephen R. Daniels, Adam Drewnowski, Francine R. Kaufman, Lawrence A. Palinkas, Arlan L. Rosenbloom, and Jeffrey B. Schwimmer. 2008. "Influence of Race, Ethnicity, and Culture on Childhood Obesity: Implications for Prevention and Treatment." Diabetes Care 31(11):2211-21.

Caputo, Richard K. 2003. "The Effects of Socioeconomic Status, Perceived Discrimination and Mastery on Health Status in a Young Cohort." Social Work in Health Care 37(2):17-42.

Centers for Disease Control and Prevention (CDC). 2012. Heart Disease Facts. Atlanta, GA: National Center for Chronic Disease Prevention and Health Promotion, Division for Heart Disease and Stroke Prevention. Retrieved on March 27, 2012 (http://www.cdc.gov/heartdisease/facts.htm).

Chae, David H., Karen D. Lincoln, Nancy E. Adler, and S. Leonard Syme. 2010. "Do Experiences of Racial Discrimination Predict Cardiovascular Disease among African American Den? The Moderating Role of Internalized Negative Racial Group Attitudes.” Social Science \& Medicine 71:1182-1188.

Christie-Mizell, C. André and Rebecca J. Erickson. 2007. "Mothers and Mastery: The Consequences of Perceived Neighborhood Disorder." Social Psychology Quarterly, 70: 340-365.

Christie-Mizell, C. André, Aya Kimura Ida, and Verna M. Keith. 2010. “African Americans and Physical Health: The Consequences of Self-Esteem and Happiness." Journal of Black Studies 40:1189-1211.

Clark, Rodney, Norman B. Anderson, Venessa R. Clark, David R. Williams. 1999. "Racism as a Stressor for African Americans: A Biopsychosocial Model." American Psychologist 54(10):805-816.

Cohen, Sheldon, Thomas A. Wills. 1985. "Stress, Social Support and the Buffering Hypothesis." Psychological Bulletin 98(2):310-357.

Cohen, Jacob and Patricia Cohen. 2003. Applied Multiple Regression/Correlation Analysis for the Behavioral Sciences, 3d edition. Mahwah, N.J.: Erlbaum Associates.

Colditz, Graham A., Pauline Martin, Meir J. Stampfer, Walter C. Willett, Laura Sampson, Bernard Rosner, Charles H. Hennekens, and Frank E. Speizer. 1986. "Validation of Questionnaire Information on Risk-Factors and Disease Outcomes in a Prospective Cohort Study of Women." American Journal of Epidemiology 123(5):894-900.

Cross, William E. 1991. Shades of Black: Diversity in African American Identity. Philadelphia, PA: Temple University Press. 
Demo, David H, and Michael Hughes. 1990. "Socialization and Racial Identity among Black Americans.” Social Psychology Quarterly 53(4):364-374.

Eaker, Elaine D., Lisa M. Sullivan, Margaret Kelly-Hayes, Ralph B. D’Agostino, and Emelia J. Benjamin. 2007. "Marital Status, Marital Strain, and Risk of Coronary Heart Disease or Total Mortality: The Farmingham Offspring Study." Psychosomatic Medicine 69:509-513.

Epel, Elissa S., Jue Lin, Frank H. Wilhelm, Owen M. Wolkowitz, Richard Cawthon, Nancy E. Adler, Christyn Dolbier, Wendy B. Mendes, and Elizabeth H. Blackburn. 2006. "Cell Aging in Relation to Stress Arousal and Cardiovascular Diseases Risk Factors.” Psychoneuroendocrinology 31(3):277-287.

Fang, Jing, Shantha Madhavan, and Michael H. Alderman. 1996. "The Association Between Birthplace and Mortality from Cardiovascular Causes among Black and White Residents of New York City." The New England Journal of Medicine 335(21):1545-51.

Feagin, Joe R., and Karyn D. McKinney. 2003. The Many Costs of Racism. Rowman \& Littlefield Publishers, Inc.

Fetzer Institute/National Institute on Aging Working Group. 1999. Multidimensional Measurement of Religiousness/Spirituality for Use in Health Research. Kalamazoo, MI: Fetzer Institute.

Forbes, Dorothy A. 2001. "Enhancing Mastery and Sense of Coherence: Important Determinants of Health in Older Adults." Geriatric Nursing 22:29-32.

Frieden, Thomas R. 2011. "Foreword." Pp. 1-2 in Morbidity and Mortality Weekly Report: CDC Health Disparities and Inequalities Report-United States, 201160 (Suppl) edited by R. L. Moolenaar, C. G. Casey, T. F. Rutledge, D. C. Johnson, C. B. Lansdowne, and J. D. Sokolow. Atlanta GA: Centers for Disease Control and Prevention.

Friedman, Elliot, David R. Williams, Burton H. Singer, Carol D. Ryff. 2009. "Chronic Discrimination Predicts Higher Circulating Levels of E-Selectin in a National Sample: The MIDUS Study." Brain, Behavior, and Immunity 23:684-692.

Geronimus, Arline T., Margaret Hicken, Danya Keene, and John Bound. 2006. "“Weathering" and Age Patterns of Allostatic Load Scores Among Blacks and Whites in the United States." American Journal of Public Health 96(5):826-833.

Geronimus, Arline T. and J. Phillip Thompson. 2004. "To Denigrate, Ignore, or Disrupt: Racial Inequality in Health and Impact of a Policy-Induced Breakdown of Black American Communities." DuBois Review: Social Science Research on Race $1(2): 247-279$. 
Goodstein, Renee and Joseph G. Ponterotto. 1997. "Racial and Ethnic Identity: Their Relationship and Their Contribution to Self-Esteem." Journal of Black Psychology 23(3):275-292.

Griffith, Derek M., Jonetta L. Johnson, Rong Zhang, Harold W. Neighbors, and James S. Jackson. 2011. "Ethnicity, Nativity, and the Health of American Blacks." Journal of Health Care for the Poor and Underserved 22(1):142-56.

Guyll, Max, Karen A. Matthews, and Joyce T. Bromberger. 2001. "Discrimination and Unfair Treatment: Relationship to Cardiovascular Reactivity among African American and European American Women." Health Psychology 20(5):315-325.

Harlow, Siobán D. and Martha S. Linet. 1989. “Agreement Between Questionnaire Data and Medical Records: The Evidence for Accuracy of Recall." American Journal of Epidemiology 129(2):233-248.

Hummer, Robert A., Richard G. Rogers, Charles B. Nam, and Christopher G. Ellison. 1999. "Religious Involvement and U.S. Adult Mortality." Demography 36(2):273-285.

Ida, Aya Kimura and C. André Christie-Mizell. 2012. "Racial Group Identity, Psychosocial Resources, and Depressive Symptoms: Exploring Ethnic Heterogeneity among Black Americans." Sociological Focus 45(1):41-62.

Jackson, James S., Tony N. Brown, David R. Williams, Myriam Torres, Sherrill L. Sellers, and Kendrick Brown. 1996. "Racism and the Physical and Mental Health Status of African Americans: A Thirteen Year National Panel Study." Ethnicity and Disease 6(1,2):132-147.

Jackson, James S., Myriam Torres, Cleopatra H. Caldwell, Harold W. Neighbors, Randolph M. Nesse, Robert Joseph Taylor, Steven J. Trierweiler, and David R. Williams. 2004a. "The National Survey of American Life: A Study of Racial, Ethnic and Cultural Influences on Mental Disorders and Mental Health.” International Journal of Methods in Psychiatric Research 13(4):196-207.

Jackson, James S., Harold W. Neighbors, Randolph M. Nesse, Steven J. Trierweiler, and Myriam Torres. 2004b. "Methodological Innovations in the National Survey of American Life." International Journal of Methods in Psychiatric Research 13:289-298.

Jaret, Charles and Donald C. Reitzes. 1999. “The Importance of Racial-Ethnic Identity and Social Setting for Blacks, Whites, and Multiracials." Sociological Perspectives 42(4):711-737. 
Jenkins, C. David. 1976. "Recent Evidence Supporting Psychologic and Social Risk Factors for Coronary Heart Disease." New England Journal of Medicine 294(18):987-994.

Johnson, Norman J., Erick Backlund, Paul D. Sorlie, and Catherine A Loveless. 2000. "Marital Status and Mortality: The National Longitudinal Mortality Study." Annals of Epidemiology 10(4):224-238.

Kalmijn, Matthijs. 1996. "The Socioeconomic Assimilation of Caribbean American Blacks.” Social Forces 74(3): 911-930.

Keenan, Nora L. and Kate M. Shaw. 2011. "Coronary Heart Disease and Stroke DeathsUnited States, 2006." Pp. 62-65 in Morbidity and Mortality Weekly Report: CDC Health Disparities and Inequalities Report-United States, 201160 (Suppl) edited by R. L. Moolenaar, C. G. Casey, T. F. Rutledge, D. C. Johnson, C. B. Lansdowne, and J. D. Sokolow. Atlanta GA: Centers for Disease Control and Prevention.

Kent, Mary Mederios. 2007. "Immigration and America's Black Population," Population Bulletin 62(4).

Kessler, Ronald C., Kristin D. Mickelson, and David R. Williams. 1999. "The Prevalence, Distribution, and Mental Health Correlates of Perceived Discrimination in the United States." Journal of Health and Social Behavior 40(3):208-230.

Koenig, Harold G. 2004. "Religion, Spirituality, and Medicine: Research Findings and Implications for Clinical Practice.” Southern Medical Journal 97(12):1194-1200.

Krieger, Nancy, and Stephen Sidney. 1996. "Racial Discrimination and Blood Pressure: The CARDIA Study of Young Black and White Women and Men. American Journal of Public Health 86(10):1370-78.

LaVeist, Thomas A., Robert Seller, and Harold W. Neighbors. 2001. "Perceived Racism and Self and System of Blame Attribution: Consequences for Longevity." Ethnicity \& Disease 11(4):711-21.

Lewis, Tené T. 2011. "Self-Reported Experiences of Discrimination and Visceral Fat in Middle-Aged African-American and Caucasian Women." American Journal of Epidemiology 173(11):1223-1231.

Massey, Douglas S. 2004. "Segregation and Stratification: A Biopsychosocial Perspective." DuBois Review: Social Science Research on Race 1(1):7-25. 
McEwen, Bruce S. 1998. "Stress, Adaptation, and Disease: Allostasis and Allostatic Load." Annals of the New York Academy of Sciences 840(1 neuroimmunomo):3344.

McFadden, John and James L. Moore III. 2001. "Intercultural Marriage and Intimacy: Beyond the Continental Divide." International Journal for the Advancement of Counselling 23:261-268.

Mezuk Briana. 2010. "Epidemiology of Diabetes and Cardiovascular Disease: The Emergence of Health Disparities over the Life Span.” Pp. 77-97 in Health Inequalities: Life Course Perspectives on Late Life Outcomes, edited by T.C. Antonucci and J.S. Jackson. New York, NY: Springer Publishing.

Nerem, Robert M., Murina J. Levesque, and J. Fredrick Cornhill. 1980. "Social Environment as a Factor in Diet-Induced Atherosclerosis." Science 208(4451):1475-1476.

Nguyen, Kim Hahn, S.V. Subramanian, Glorian Sorensen, Kathy Tsang, Rosalind J. Wright. 2010. "Influence of Experiences of Racial Discrimination and Ethnic Identity on Prenatal Smoking Among Urban Black and Hispanic Women." Journal of Epidemiology and Community Health 66:315-321.

Parker, Vanessa, Steve Sussman, David Crippens, Pam Elder, and Donna Scholl. 1998. "The Relation of Ethnic Identification with Cigarette Smoking Among US Urban African American and Latino Youth: A Pilot Study." Ethnicity \& Health 3(12):135-143.

Pascoe, Elizabeth A. and Laura Smart Richman. 2009. "Perceived Discrimination and Health: A Meta-Analytic Review.” Psychological Bulletin 135(4):531-554.

Pearlin, Leonard I. 1989. "The Sociological Study of Stress." Journal of Health and Social Behavior 30(3):241-256.

Pearlin, Leonard I., Morton A Liberman, Elizabeth G. Menaghan, and Joseph T. Mullan. 1981. "The Stress Process." Journal of Health and Social Behavior 2:337-356.

Phinney, Jean S. 1996. "Understanding Ethnic Diversity: The Role of Ethnic Identity." The American Behavioral Scientist 40(2):143-152.

Phinney, Jean S. 1990. "Ethnic Identity in Adolescents and Adults: Review of Research." Psychological Bulletin 108(3):499-514.

Pickering, Thomas. 1999. "Cardiovascular Pathways: Socioeconomic Status and Stress Effects on Hypertension and Cardiovascular Function." Annals of the New York Academy of Sciences 896:262-277. 
Powell, Lynda H., Leila Shahabi, and Carl E. Thoresen. 2003. "Religion and Spirituality: Linkages to Physical Health.” American Psychologist 58(1):36-52.

Pudrovska, Tetyana, Scott Schieman, Leonard I. Pearlin, and Kim Nguyen. 2005. "The Sense of Mastery as a Mediator and Moderator in the Association Between Economic Hardship and Health in Late Life. Journal of Aging and Health 17:634660.

Read, Jen'nan Ghazal and Michael O. Emerson. 2005. "Racial Context, Black Immigration and U.S. Black/White Health Disparity." Social Forces 84(1):181199.

Read, Jen'nan Ghazal, Michael O. Emerson, and Alvin Tarlov. 2005. "Implications of Black Immigrant Health for U.S. Racial Disparities in Health.” Journal of Immigrant Health 7(3):205-12.

Rosenberg, Morris. 1965. Society and the Adolescent Self-Image. Princeton, NJ: Princeton University Press.

Rozanksi, Alan, James A. Blumenthal, and Jay Kaplan. 1999. "Impact of Psychological Factors on the Pathogenesis of Cardiovascular Disease and Implications for Therapy." Circulation 99:2192-2217.

Russek, Linda G., Stanley H. King, Shelley J. Russek, and Henry I. Russek. 1990. "The Harvard Mastery of Stress Study 35-year Follow-up: Prognostic-Significant Patterns of Psychophysiological Arousal and Adaptation." Psychosomatic Medicine 52(3):271-285.

Seeman, Teresa E., Eileen Crimmins, Mei-Hua Huang, Burton Singer, Alexander Bucur, Tara Gruenewald, Lisa F. Berkman, and David B. Reuben. 2004. "Cumulative Biological Risk and Socio-economic Differences in Mortality: MacArthur Studies of Successful Aging." Social Science \& Medicine 58(10):1985-97.

Seeman, Teresa E., Bruce S. McEwen, John W. Rowe. and Burton H. Singer. 2001. "Allostatic Load as a Marker of Cumulative Biological Risk: MacArthur Studies of Successful Aging." Proceedings of the National Academy of Sciences of the United States of America 98(8):4770-5.

Sellers, Robert M. and J. Nicole Shelton. 2003. "The Role of Racial Identity in Perceived Racial Discrimination." Journal of Personality and Social Psychology 84(5): 1079-1092.

Singh, Gopal K. and Mohammad Siahpush. 2002. "Ethnic-Immigrant Differentials in Health Behaviors, Morbidity, and Cause-Specific Mortality in the United States: An Analysis of Two National Data Bases.” Human Biology 74(1):83-109. 
Shaw-Taylor, Yoku. 2007. "The Intersection of Assimilation, Race, Presentation of Self, and Transnationalism in America." Pp.1-47 in The Other African Americans: Contemporary African and Caribbean Immigrants in the United States, edited by Yoku Shaw-Taylor and Steven A. Tuch. Lanham, MD: Rowman \& Littlefield Publishers, Inc.

Shelton, Jason E. 2008. "The Investment in Blackness Hypothesis: Toward Greater Understanding of Who Teaches What during Racial Socialization." Du Bois Review: Social Science Research on Race 5:235-257.

Shelton, J. Nicole and Robert M. Sellers 2000. "Situational Stability and Variability in African American Racial Identity." Journal of Black Psychology 26(1):27-50.

Takeuchi, David T., Margarita Alegria, James S. Jackson, and David R. Williams. 2007. "Immigration and Mental Health: Diverse Findings in Asian, Black, and Latino Populations." (Editorial) American Journal of Public Health 97(1):11-12.

Thoits, Peggy. 1995. Stress, Coping, and Social Support Processes: Where Are We? What Next? Journal of Health and Social Behavior 35(Extra Issue: Forty Years of Medical Sociology: The State of the Art and Directions for the Future):53-79.

Turner, R. Jay. 2010. "Understanding Health Disparities: The Promise of the Stress Process Model." Pp 3-19 in Advances in the Conceptualization of the Stress Process: Essays in Honor of Leonard I. Pearlin, edited by William R. Avison, Carol S. Aneshensel, Scott Schieman, and Blair Wheaton. Spring Science and Business Media, LLC.

Turner, R. Jay and William R. Avison. 2003. "Status Variations in Stress Exposure: Implications for the Interpretation of Research on Race, Socioeconomic Status, and Gender. Journal of Health and Social Behavior 44(4):488-505.

Turner, R. Jay and Donald L. Lloyd. 1999. "The Stress Process and the Social Distribution of Depression." Journal of Health and Social Behavior 40:374-404.

Utsey, Shawn O., Mark H. Chae, Christa F. Brown, and Deborah Kelly. 2002. "Effect of Ethnic Group Membership on Ethnic Identity, Race-Related Stress and Quality of Life." Cultural Diversity and Ethnic Minority Psychology 8(4):366-377.

Uchino, Bert N., John T. Cacioppo and Janice K. Kiecolt-Glaser. 1996. "The Relationship Between Social Support and Physiological Processes: A Review with Emphasis on Underlying Mechanisms and Implications for Health." Psychological Bulletin 119(3):488-531.

Vitaliano, Peter P., James M. Scanlan, Jianping Zhang, Margaret V. Savage, Irl B. Hirsch, and Ilene C. Siegler. 2002. "A Path Model of Chronic Stress, the 
Metabolic Syndrome and Coronary Heart Disease." Psychosomatic Medicine 64:418-435.

Waters, Mary C. 1991. "The Role of Lineage in Identity Formation among Black Americans." Qualitative Sociology 14:57-76.

Waters, Mary C. 1999. Black Identities: West Indian Immigrant Dreams and American Realities. New York: Russell Sage Foundation and Cambridge: Harvard University Press.

Williams, David R. 1996. "Racism and Health: A Research Agenda." Ethnicity \& Disease 6(1-2):1-8.

Williams, David, Hector M. González, Harold Neighbors, Randolph Nesse, Jaime M. Abelson, Julie Sweetman, and James S. Jackson. 2007a. "Prevalence and Distribution of Major Depressive Disorder in African Americans, Caribbean Blacks, and Non-Hispanic Whites: Results From the National Survey of American Life." Archives of General Psychiatry 64(Mar): 305-315.

Williams, David R., Rahwa Haile, Hector M. González, Harold Neighbors, Raymond Baser, and James S. Jackson. 2007b. "The Mental Health of Black Caribbean Immigrants: Results from the National Survey of American Life." American Journal of Public Health 97(1): 52-58.

Williams, David R. and James S. Jackson. 2000. "Race/Ethnicity and the 2000 Census: Recommendations for African American and Other Black Populations in the United States. American Journal of Public Health 90(11):1728-30.

Williams, David R. and Selina A. Mohammed. 2009. "Discrimination and Racial Disparities in Health: Evidence and Needed Research." Journal of Behavioral Medicine 32:20-47.

Williams, David R., Selina A. Mohammed, Jacinta Leavell, and Chiquita Collins. 2010. "Race, Socioeconomic Status, and Health: Complexities, Ongoing Challenges, and Research Opportunities." Annals New York Academy of Sciences 1186:69101.

Williams, David R., Harold W. Neighbors, and James S. Jackson. 2003. "Race/Ethnic Discrimination and Health: Finding from Community Studies." American Journal of Public Health 93:200-208.

Williams, David R.,Yan Yu, James S. Jackson, and Norman B. Anderson. 1997. "Racial Differences in Physical and Mental Health: Socioeconomic Status, Stress and Discrimination." Journal of Health Psychology 2(3):335-351.

Winkleby, Marilyn A., Catherine Cubbin, David K. Ahn, and Helena C. Kraemer. 1999. 
"Pathways by Which SES and Ethnicity Influence Cardiovascular Disease Risk Factors." Annals New York Academy of Sciences 896:191-209. 